\title{
DOSE-DEPENDENT UPTAKE, ELIMINATION, AND TOXICITY OF MONOSODIUM METHANEARSONATE IN ADULT ZEBRA FINCHES (TAENIOPYGIA GUTTATA)
}

\author{
Courtney A. Albert, $\dagger$ Tony D. Williams, $\dagger$ Christy A. Morrissey, $\neq$ Vivian W.M.-Lai, $\S$ \\ William R. Cullen, $\S$ and John E. ElliotT* $*$ \\ $\dagger$ Biological Sciences, 8888 University Drive, Simon Fraser University, Burnaby, British Columbia V5A 1S6, Canada \\ $\ddagger$ Science and Technology Branch, Environment Canada, Pacific Wildlife Research Centre, 5421 Robertson Road, Delta, \\ British Columbia V4K 3N2, Canada \\ §Chemistry Department, Room W300 - 6174 University Boulevard, Vancouver, British Columbia V6T 1Z3, Canada
}

(Received 21 February 2007; Accepted 16 August 2007)

\begin{abstract}
Monosodium methanearsonate (MSMA), an arsenic-based pesticide, has been used for the past 10 years in attempts to suppress mountain pine beetle (Dendroctonus ponderosae) outbreaks in British Columbia, Canada. Previous studies have shown that cavity nesting forest birds such as woodpeckers forage and breed in MSMA treated pine stands. Here we examined the effects of MSMA in the laboratory using the zebra finch (Taeniopygia guttata), with the objective to examine tissue distribution and sublethal toxic effects in a model avian species. Zebra finches were exposed to this pesticide at doses similar to those found in bark beetle samples from MSMA stands of trees treated in the southern interior of British Columbia $(8,24$, and $72 \mu \mathrm{g} / \mathrm{g} / \mathrm{d}$ and a control group). Results showed high excretion (>90\%) of arsenic in all dose groups, as well as dose-dependent trends in accumulation of arsenic in the blood $(p<0.001)$ and specific tissues. Monomethylarsonic acid, MMA (V), was the predominant form of arsenic in the blood plasma. Dimethylarsinic acid was the major form of arsenic found in the liver $(83 \%)$ and kidney $(61 \%)$ tissues. The brain tissue contained primarily the MMA (V) form (57\%). Significant weight loss occurred in the two highest dose groups $(p<$ 0.05). Birds in the highest dose group lost up to $15 \%$ of initial body mass.
\end{abstract}

Keywords-Monosodium methanearsonate Pesticides Mountain pine beetle Zebra finches

\section{INTRODUCTION}

Monosodium methanearsonate, or MSMA, is a highly water-soluble crystalline solid containing arsenic in the pentavalent form. Monosodium methanearsonate has been used as an herbicide and defoliant and has been recently used as a pesticide to suppress mountain pine beetle (Dendroctonus ponderosae) outbreaks in pine forests across British Columbia, Canada. The commercial formula of MSMA used in British Columbia is called Glowon ${ }^{\circledR}$ (United Agri, London, ON, Canada). Approximately $960 \mathrm{~kg}(0.77 \mathrm{~kg} / \mathrm{L}$ Glowon) of this product has been used annually in British Columbia [1]. Application rates require approximately $1 \mathrm{ml}$ of Glowon $(0.32 \mathrm{~kg}$ elemental arsenic [as MSMA]/L water and additives) per 2.5 $\mathrm{cm}$ of tree circumference (http://www.for.gov.bc.ca/tasb/ legsregs/fpc/fpcguide/beetle/betletoc.htm) and in the Cascades Forest District alone, over 60,000 trees were treated between 2000 and 2004 [2], with little knowledge of potential exposure or effects in nontarget wildlife. For example, few studies have examined the acute toxicity of MSMA in avian systems. In one study, for 17-week-old bobwhite quail (Colinus virginianus) the acute $96 \mathrm{~h} \mathrm{LD50}$ was $834 \mathrm{mg} / \mathrm{kg}$ MSMA. Oral acute 96-h LD50 values in 10-d old bobwhite quail were approximately $650 \mathrm{mg} / \mathrm{kg} / \mathrm{d}$ [3]. Similarly, very few studies have examined tissue distribution and speciation of MSMA in any terrestrial animal. Studies using laboratory or domesticated mammals suggest that orally administered MSMA can increase arsenic levels transiently, sometimes to high concentrations, in specific tissues, but most of the arsenic ( $>90 \%)$ is rapidly

* To whom correspondence may be addressed (john.elliott@ec.gc.ca).

Published on the Web 11/7/2007. excreted, and that tissue levels decrease to normal upon cessation of dosing [4,5].

The toxicity of arsenic depends on the species of arsenic, the oxidation state, and animal species exposed. Trivalent arsenicals are more cytotoxic than pentavalent arsenicals [6,7] and among the methylated arsenicals, methylarsonous acid, MMA (III), has been shown to be the most toxic species [7,8]. Biotransformation of MSMA and other methylated arsenicals occurs following ingestion by an animal, and dimethylarsinic acid (DMA) is the most common metabolite and the primary excretory form in mammals [9] (Fig. 1). Therefore, while MSMA may be less acutely toxic than other arsenic species, oral routes of exposure of MSMA may produce more toxic metabolites, such as MMA (III), during biotransformation to DMA in vivo. Exact mechanisms of toxicity of MSMA to exposed animals are not well known. In general, arsenic is a toxic metalloid with multiple effects. It has been suggested that arsenic is directly toxic through binding to sulfhydryl groups in proteins and altering their functions [10]. Methylated trivalent arsenicals such as MMA (III) can inhibit enzymes such as glutathione reductase [11] altering cellular redox reactions and leading to cytotoxicity [12]. Carcinogenicity of arsenic is well known in humans and speculated in many animals [12]. Methylated pentavalent arsenicals have been shown to be genotoxic, with effects such as excess tetraploidy [13] and mitotic arrest [14]. Additionally, DMA (V), MMA (III), and DMA (III) have been shown to increase cell proliferation in the development of cancer [15], and DMA (V) is a tumor promoter in several organ tissues of the mouse and rat $[15,16]$. Throughout the literature, monomethylarsonic acid is abbreviated as MMA, MAA, MMAA, and MMAs. To avoid any confusion, MMA will be used throughout the present paper. 
MMA

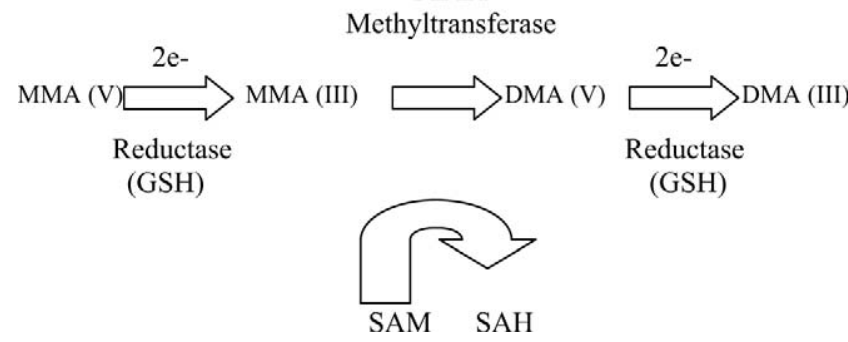

Fig. 1. Proposed metabolic pathway: Monomethylarsonic acid (V) is first reduced to MMA (III), followed by further methylation to dimethylarsinic acid (V) and possible reduction to DMA (III). Glutathione (GSH) and other thiols serve as reducing agents, and S-adenosylmethionine (SAM) is the main methyl donor, which is converted to S-adenosylhomocysteine (SAH).

In British Columbia, we were concerned primarily with MSMA exposure to woodpeckers and other cavity nesting forest birds that feed on the mountain pine beetle. Woodpeckers can have winter diets of up to $99 \%$ beetle adults and larvae [17], with three-toed (Picoides tridactylus) and hairy (P. villosus) woodpeckers ingesting many thousands of beetles and larvae per day [18]. In areas where mountain pine beetle outbreaks occur, woodpeckers locally increase in number $[17,18]$, which suggests that they are attracted to areas of high beetle density. Recent studies in the Merritt Forest District of British Columbia have shown that arsenic can accumulate in beetles in MSMA treated stands of pine trees, and that three-toed and hairy woodpeckers forage in those pine stands [2].

Our main objectives were to use the zebra finch (Taeniopygia guttata) as a model species to measure uptake, excretion, and metabolism of arsenic in adult birds orally dosed with different concentrations of MMA (V) (0, 8, 24, and 72 $\mu \mathrm{g} / \mathrm{g}$, respectively). Additionally, we wanted to determine speciation of arsenic in tissues and excreta of zebra finches orally dosed with MMA (V). Our final objective was to consider the implications for birds in the wild, such as woodpeckers, exposed to MSMA. We hypothesize that if birds metabolize MMA (V), metabolites such as DMA will be present in the excrement. Furthermore, if little to no metabolism of MMA (V) occurs it should be excreted in its original form.

\section{METHODS}

\section{Animals and husbandry}

The present study was conducted using a laboratory colony of zebra finches maintained at the Simon Fraser University Animal Care Facility (Burnaby, BC, Canada). Finches were maintained in Canadian Committee on Animal Care accredited facilities, with a constant $14: 10 \mathrm{~h}$ light:dark cycle at 19 to $23^{\circ} \mathrm{C}$ and 35 to $55 \%$ humidity. Experiments and animal husbandry were conducted under a Simon Fraser University Animal Care Committee permit (666B-03). All work was done following Canadian Committee on Animal Care guidelines (http://www.ccac.ca/en/ CCAC_Programs/Guidelines_Policies/GUIDES/ENGLISH/toc_ v1.htm). For these experiments, birds were held in cages $(61 \times$ $46 \times 41 \mathrm{~cm}$ ) with three to six birds per cage. All birds were allowed free access to a mixed seed diet (Panicum and white millet, 50:50; approximately $12.0 \%$ protein, $4.7 \%$ lipid) and water, grit, and cuttlefish bone ad libitum.

\section{Experimental groups and dosing procedure}

For the present study, 21 female zebra finches were randomly assigned to one of four experimental groups, which included a low dose of $8.0 \mu \mathrm{g}$ MMA/g body weight/d (one cage $\times$ six birds), a medium dose of $24.0 \mu \mathrm{g} \mathrm{MMA} / g$ body weight/d (one cage $\times$ six birds) and a high dose of $72.0 \mu \mathrm{g}$ MMA/g body weight/d (one cage $\times$ six birds). A control group was dosed with deionized distilled water only (one cage $X$ three birds). Monomethylarsonic acid was used in the present study as it is equivalent to MSMA at gastrointestinal $\mathrm{pH}$ [1], and is the primary form of arsenic detected in the bark beetle samples collected in MSMA treated pine stands in British Columbia [2]. Technical grade MMA (V) was used in the present study. Solution concentrations were calculated assuming a zebra finch would receive $0.1 \mathrm{ml}$ of the MMA (V) solution each day, and this was based on a $15 \mathrm{~g}$ zebra finch. A stock solution of the high $(72 \mu \mathrm{g} / \mathrm{g})$ concentration was made and serial dilutions were carried out to make the medium (24 $\mu \mathrm{g} / \mathrm{g})$ and low $(8 \mu \mathrm{g} / \mathrm{g})$ solutions. For the stock solution, the compound was dissolved in deionized distilled water $(0.648$ $\mathrm{g}$ of MMA (V) per $60 \mathrm{ml}$ water for stock solution). In order to validate the dosing solution concentrations, the solutions were analyzed (William Cullen, University of British Columbia) prior to administration. Birds were fasted overnight and dosed between 8:00 to 10:00 AM Pacific Standard Time for $14 \mathrm{~d}$. Approximately $0.1 \mathrm{ml}$ of the MMA-water solution was administered via intubation. Exact administered volumes of the solution were separately calculated within each dose group for each bird depending on individual body mass. Birds were orally dosed daily using a micropipette for the early stages and a syringe with a gavage attachment once birds reached an appropriate size $(\sim 10 \mathrm{~d}$ old). Spillage was negligible and we can assume there were no discrepancies in the amount of MMA solution administered to the birds. Birds were given food and water between 10 and 20 min after being dosed. Body mass and general health of each bird was observed and recorded daily. Wax paper was laid down immediately after dosing to collect excreta.

Excreta samples were collected daily, approximately $24 \mathrm{~h}$ after being dosed, and pooled per cage (each cage represented a separate dose group). Excreta were collected using acidwashed (10\% nitric acid for $24 \mathrm{~h})$ plastic spoons, and stored in sterile plastic bags. Excreta samples were frozen immediately after collection and freeze dried prior to analysis. It is important to note that birds excrete urine and feces together. Therefore we use the term excreta to represent both urine and feces.

\section{Dosage rationale and environmental relevance}

Dose calculations were based on arsenic concentrations in bark beetles collected in the Merritt forest district, where MSMA has been used extensively, and on daily food requirements for three species of woodpeckers. Mountain pine beetle samples contained up to $350 \mu \mathrm{g} / \mathrm{g}$ dry weight total arsenic, with MMA(V) species contributing to over $90 \%$ of the total [2]. Therefore, the dosing scheme used in this experiment was based on $0,50,150$, and $450 \mu \mathrm{g} / \mathrm{g}$ in beetle prey to encompass the range of MMA (V) concentrations found in the bark beetle samples. Elemental arsenic represents $54 \%$ of the total molecular weight of MMA (V). Therefore, our actual elemental arsenic doses are approximately half of the administered MMA (V) doses. However, woodpeckers are actually ingesting primarily $(>90 \%)$ MMA (V) in the bark beetles. Thus, in order to remain consistent with our environmental relevance in this experiment, we based the dosing scheme on total ingested MMA (V). 
Based on daily food requirements of wild insectivorous birds [19], woodpeckers require an average of approximately $10.5 \mathrm{~g}$ of dry matter intake (DMI) per day. This average daily DMI was based on the average body mass of three-toed (65.7 $\mathrm{g}$ ), black-backed (P. arcticus) (69.3 g), and hairy (66.3 g) woodpeckers [20], which was calculated to be $67.1 \mathrm{~g}$. In order to calculate a daily dose for the lowest dose group (50 $\mu \mathrm{g} / \mathrm{g}$ ) we multiplied the MMA (V) concentrations in the bark beetles by an average daily DMI $(10.5 \mathrm{~g} / \mathrm{d})$, which gives a total daily MMA (V) intake of $525 \mu \mathrm{g} / \mathrm{d}$ for woodpeckers. We then divided the estimated total daily MMA (V) intake by the average body mass woodpecker $(67.1 \mathrm{~g})$ [19]. This yields a daily dose of approximately $8 \mu \mathrm{g}$ arsenic/g body mass/d. Therefore, dosages were $0,8,24$, and $72 \mu \mathrm{g} / \mathrm{g}$ MMA (V) per day. These doses were extrapolated to the laboratory colony of zebra finches based on their individual mass. Volumes administered were calculated daily based on their daily mass.

\section{Blood and tissue sample collection}

After 14 d of MMA (V) dosing all 21 birds were anesthetized via an intramuscular injection of $50 \mu \mathrm{l}$ ketamine and xylazine solution (50:50 by volume; Associated Veterinary Products, Abbotsford, BC, Canada) followed by exsanguination. Whole blood samples were collected to determine total arsenic content, and were taken via both the jugular and brachial veins using heparinized pipettes and transferred to heparinized centrifuge tubes. Within $4 \mathrm{~h}$ of being collected, a subset of the blood samples (one blood sample from each dose group, total three blood samples) were separated into plasma and red blood cells by centrifuging for $15 \mathrm{~min}$ at 5,000 rpm (Baxter CanLab Biofuge 13, Simon Fraser University, Burnaby, BC, Canada) and immediately frozen at $-20^{\circ} \mathrm{C}$. Red blood cell samples were then freeze dried prior to analysis.

Additional blood samples were taken using a heparinized capillary tube to determine hematocrit and leucocrit. Hematocrit is a measure of the percentage of red blood cells to the total volume of a blood sample [21], and leucocrit is a measure of the percentage of white blood cells to the total volume of a blood sample [22]. Blood was kept cold and within $4 \mathrm{~h}$ of collection, the blood was centrifuged for $3 \mathrm{~min}$ at 5,000 rpm and the height of the leucocrit, hematocrit, and total sample was then measured using a digital caliper $(0.01 \mathrm{~mm})$. To remain consistent, all measurements of hematocrit and leucocrit were made by the same researcher. Liver, kidney, brain, and carcass tissues were obtained through dissection and were frozen at $-20^{\circ} \mathrm{C}$ prior to being freeze dried and analyzed for arsenic.

\section{MMA (V) analysis}

Arsenic species analyzed included MMA (V), which is the original dosing compound; DMA (V), which is the metabolite of MMA and is the predominant excretory form in mammals; and inorganic arsenic, As (V). Solutions, blood, excreta, organ, and carcass tissues were sent to William Cullen's chemistry laboratory at the University of British Columbia where they were measured for arsenic content and speciation. Solutions were analyzed before dosing to confirm MMA (V) concentrations. For total arsenic analysis, whole blood samples were analyzed for each individual bird in all four dose groups, whereas excreta samples comprised pooled samples from six birds per cage per treatment. Excreta samples from each treatment group on MMA (V) treatment days 1, 7, and 14 were analyzed for total arsenic. Organ samples were also pooled (two birds per single analysis) to ensure adequate levels of arsenic for detection. Organ samples were analyzed for all dose groups. Carcass samples were analyzed individually. For arsenic speciation analysis, one plasma sample from each treatment group was analyzed ( $n=3$ plasma samples). Control samples were not analyzed for speciation. Only excreta samples from the highest dose group $(72 \mu \mathrm{g} / \mathrm{g})$ from treatment days 1,7 , and 14 and only organs from the highest dose group were analyzed for arsenic speciation.

Once organs were extracted from the bodies, the feathers, feet, and beaks were removed and the remaining carcasses were freeze-dried. Individual dried carcasses were then homogenized using a food processor, taking all precautions necessary to avoid cross-contamination of different dose groups. Freeze-dried red blood cells, excreta, organ, and carcass tissue samples were weighed into centrifuge tubes (either $15 \mathrm{ml}$ or $50 \mathrm{ml})$ and $5 \mathrm{ml}$ of a methanol/water mixture $(1: 1, \mathrm{v} / \mathrm{v})$ was added to each tube. Tubes were then sonicated for $10 \mathrm{~min}$ and centrifuged $(3,000 \mathrm{rpm})$ for $10 \mathrm{~min}$, and the supernatant was removed by means of a Pasteur pipette and placed in a round bottom flask. This extraction procedure was repeated four times for each sample. The combined supernatants were evaporated to dryness and dissolved in $10 \mathrm{ml}$ of deionized water prior to further analysis. Extracts were stored at $-20^{\circ} \mathrm{C}$ and transferred to the cold room $\left(\sim 4^{\circ} \mathrm{C}\right)$ on the day of analysis [23].

Plasma samples were cleaned using Microcon ${ }^{\circledR}$ centrifugal filter devices (model YM-3, 3,000 nominal molecular weight limit, Millipore, (Bedford, MA, USA) by centrifugation for $100 \mathrm{~min}$ at $14,000 \mathrm{~g}$. Cleaned samples were stored at $-20^{\circ} \mathrm{C}$ and transferred to the cold room $\left(\sim 4^{\circ} \mathrm{C}\right)$ on the day of analysis [23].

Plasma and tissue sample extracts were analysed for arsenic speciation using high performance liquid chromatography-inductively coupled plasma mass spectrometry. Arsenic compounds in the samples were identified by matching the retention times of the peaks in the chromatograms with those of known standards. Quantification was done by comparing peaks with those of matching standards [23].

Solid red blood cells, tissue and fecal samples were weighed into glass test tubes (outer diameter $16 \mathrm{~mm}$ ). Two milliliters of nitric acid and three Teflon ${ }^{\circledR}$ boiling chips were added to each tube. The samples were heated in a test tube block heater at temperatures increasing stepwise from 70 to $150^{\circ} \mathrm{C}$ and then cooled overnight. Hydrogen peroxide $(2 \mathrm{ml})$ was added into the samples on the next day and the samples were heated to $150^{\circ} \mathrm{C}$ until they were evaporated to dryness. The residue was redissolved in $4 \mathrm{ml}$ of an aqueous solution containing $1 \%(\mathrm{v} /$ v) nitric acid and $5 \mathrm{ppb}$ rhodium. The samples were mixed thoroughly by using a vortex mixer and filtered $(0.45 \mu \mathrm{m})$. The samples were stored at $4^{\circ} \mathrm{C}$ until analysis. Digested red blood cells, excreta, and tissue samples were then analyzed for total arsenic using inductively coupled plasma mass spectrometry [23].

All reagents used were of high purity, suitable for highperformance liquid chromatography-inductively coupled plasma mass spectrometry analysis. Quality assurance included the analysis of the standard reference materials: dogfish muscle from the National Research Council (Ottawa, ON, Canada) and fucus sample (IAEA-140) from the International Atomic Energy Agency (Toronto, ON, Canada). Kelp powder was also used as a laboratory standard [23]. Our speciation analysis is unable distinguish between different valences. Therefore, we report MMA (V) and DMA (V) to represent both valences 


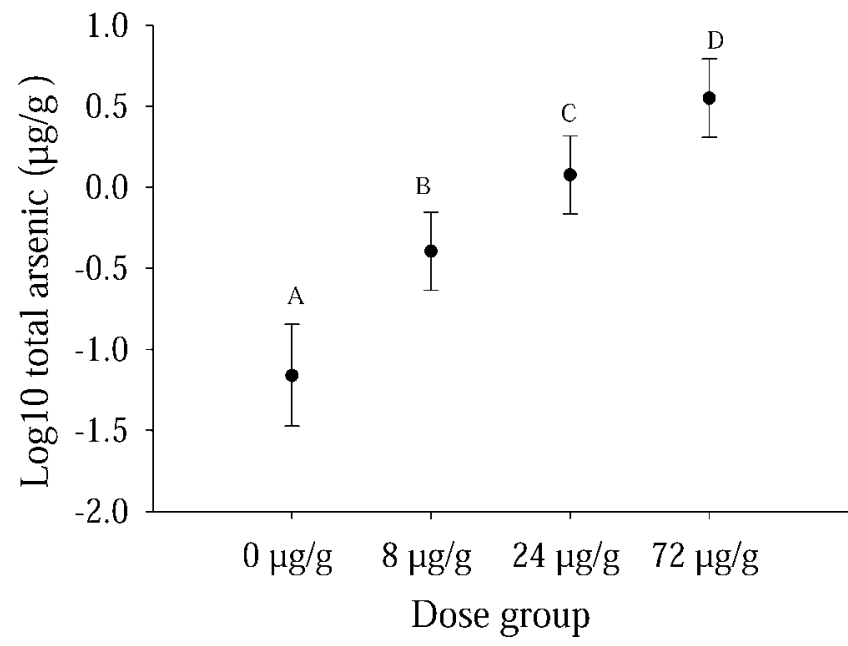

Fig. 2. Total arsenic detected in whole blood samples $(\mu \mathrm{g} / \mathrm{g}$ dry wt blood) from zebra finches orally dosed with 8,24 , and $72 \mu \mathrm{g} / \mathrm{g}$ monomethylarsonic acid and a control. Mean blood values were analyzed using analysis of variance. Values given are the mean \pm standard error. Different letters indicate significant difference at $p<0.05$.

(III) and (V). The concentrations are expressed in micrograms per gram based on dry weights.

\section{Statistical analysis}

Blood arsenic data deviated significantly from normality (Shapiro-Wilks W test, Ver 5.0, JMP, SAS Institute, Cary, NC, USA), and therefore data were $\log _{10}$ transformed prior to analysis to meet assumptions of normality for subsequent parameteric statistical analyses. Proportional data, namely hematocrit and leucocrit data, were arcsine transformed. Analysis of variance (ANOVA) was used to determine if a difference existed in total blood arsenic and percent hematocrit and leucocrit in birds exposed to control, low, medium, and high levels of MMA (V). Where differences were found, Tukey's honestly significant difference tests were used to identify which treatment levels differed significantly in their response to MMA (V) exposure. To determine whether body mass changed with time among dose groups, a repeated measures ANOVA was conducted.

\section{RESULTS}

\section{Total arsenic residues}

Whole blood arsenic varied significantly among the four dose groups, in a dose-dependent manner (ANOVA, $F_{3,53}=$ 31.7, $p<0.001$; Fig. 2). All treatment groups were significantly different from each other ( $p<0.05$ in all cases). The mean ratio of arsenic concentrations in the blood for low, medium, and high dose groups was 1:3:9, close to that of the dosing solutions, i.e., 1:3:8. Control birds had trace amounts of arsenic in the blood, which can likely be attributed to background levels resulting from natural exposure of arsenic in drinking water and food. All organ tissues contained total arsenic residues that increased with increasing dose (Table 1). To ensure quantification, organs from two individuals were pooled, so each value represents one pooled sample, and therefore no statistical analyses were possible. Brain tissue contained the highest levels of arsenic, followed by the kidney and finally the liver (Table 1).

In carcasses, there were differences in mean total arsenic between dose groups, with carcasses from the high dose group
Table 1. Concentrations of total arsenic detected in tissue samples of zebra finches dosed with monomethylarsonic acid. Liver, kidney, and brain values represent a pooled sample of two birds. Carcass values are expressed as the mean \pm standard error with sample sizes in parentheses. Different letters indicate significant difference at $p<$ 0.05

\begin{tabular}{llclr}
\hline & \multicolumn{4}{c}{ Tissue residues $(\mu \mathrm{g} / \mathrm{g})$} \\
\cline { 2 - 5 } $\begin{array}{l}\text { Dose group } \\
(\mu \mathrm{g} / \mathrm{g})\end{array}$ & Liver & Kidney & Brain & \multicolumn{1}{c}{ Carcass } \\
\hline 0 (control) & 0.05 & 0.1 & 0.05 & $0.24 \pm 1.91(3) \mathrm{B}$ \\
8 (low) & 0.1 & 0.3 & 0.2 & $1.33 \pm 1.36(6) \mathrm{B}$ \\
24 (medium) & 0.1 & 0.4 & 0.7 & $3.13 \pm 1.49(5) \mathrm{B}$ \\
72 (high) & 1.1 & 1.6 & 3.7 & $12.31 \pm 1.36(6) \mathrm{A}$ \\
\hline
\end{tabular}

(72 $\mu \mathrm{g} / \mathrm{g}$ ) having significantly higher total arsenic than all other treatment groups (ANOVA, $F_{3,19}=14.7, p<0.001$; Table 1). On average, the zebra finches in the present study retained in the tissues and organs less than $1 \%$ of the total arsenic detected over the 14-d period. The majority of the remaining arsenic is likely excreted, as the fecal samples contained the highest total arsenic concentrations. Overall, total arsenic in excreta samples increased with dose group (Fig. 3). Excreta was pooled per cage, so again each value comprised $n=1$ and therefore no statistical analyses were conducted.

\section{Arsenic speciation}

For birds in all three dose groups, MMA (V) was the predominant form of arsenic in the blood plasma, while only trace amounts of the metabolite DMA was detected in the medium and high dose groups (1-2\%). No inorganic arsenic was found in the plasma of birds in any of the three dose groups.

Dimethylarsinic acid (V) was the major form of arsenic found in the liver (83\%) and kidney (61\%) tissues of high dose group birds, with MMA (V) as the other predominant form detected in these tissues. The brain tissue contained the original unmetabolized MMA (V) form (57\%), along with a relatively large amount of DMA (V) (43\%). Inorganic arsenic was only detected in the liver tissue and in trace amounts $(5 \%)$.

Excreta samples from high dose birds on day 1, 7, and 14 contained arsenic primarily in the original MMA (V) form. Dimethylarsinic acid (V) was detected on day 1 in small

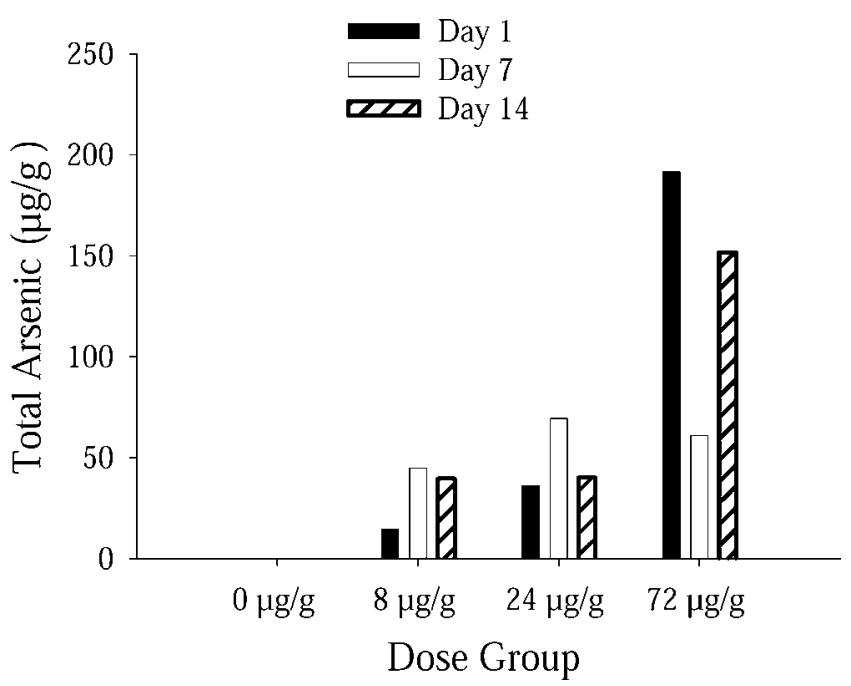

Fig. 3. Total arsenic detected in excreta samples of zebra finches dosed with monomethylarsonic acid (MMA (V)) on day $1(\square), 7(\square)$, and $14(\bigotimes)$. Data are based on pooled samples. 
Table 2. Comparison of mass change and hematological parameters in zebra finches dosed with monomethylarsonic acid for $14 \mathrm{~d}$. Values are expressed as the mean \pm standard error, and sample size is stated in parentheses. Significant values are italicized. Different letters indicate significant difference at $p<0.05$

\begin{tabular}{|c|c|c|c|c|c|}
\hline \multirow{2}{*}{$\begin{array}{l}\text { Dosage group } \\
(\mu \mathrm{g} / \mathrm{g})\end{array}$} & \multicolumn{2}{|c|}{ Mean body mass } & \multirow{2}{*}{$\begin{array}{l}\text { Mean change in } \\
\text { mass }(\mathrm{g})\end{array}$} & \multirow[b]{2}{*}{ Hematocrit (\%) } & \multirow[b]{2}{*}{ Leucocrit (\%) } \\
\hline & Day $1(\mathrm{~g})$ & Day $14(\mathrm{~g})$ & & & \\
\hline 0 (control) & $15.65 \pm 0.75$ & $15.18 \pm 0.95$ & $0.47 \pm 0.59(3) \mathrm{B}$ & $56.33 \pm 2.77(3)$ & $4.67 \pm 1.86(3)$ \\
\hline 8 (low) & $14.69 \pm 0.53(6)$ & $14.16 \pm 0.67(6)$ & $0.53 \pm 0.42(6) \mathrm{B}$ & $54.97 \pm 1.96(6)$ & $9.00 \pm 1.32(6)$ \\
\hline 24 (medium) & $14.91 \pm 0.53(6)$ & $13.74 \pm 0.67(6)$ & $1.17 \pm 0.42(6) \mathrm{A}$ & $56.98 \pm 1.96(6)$ & $4.83 \pm 1.32(6)$ \\
\hline 72 (high) & $14.87 \pm 0.53(6)$ & $12.53 \pm 0.67(6)$ & $2.24 \pm 0.42(6) \mathrm{A}$ & $59.35 \pm 2.40$ & $5.5 \pm 1.62$ \\
\hline$p$ value & 0.764 & 0.155 & 0.029 & 0.577 & 0.137 \\
\hline
\end{tabular}

amounts (8\%), increased by day $7(17 \%)$, and decreased by day $14(4 \%)$. The birds excreted no inorganic arsenic during this time period.

\section{General health measures and body mass}

Zebra finches dosed with MMA (V) did not show any signs of lethargy or diarrhea, and there was no change in the appearance or quantity of feces. Mass loss over the 14-d treatment period was significantly related to MMA (V) dose (repeated measures ANOVA, $F_{3,20}=3.85, p<0.05$ ). Birds in the control and low MMA (V) dose groups showed no change in body mass over the 14-d treatment period (paired $t$ test, $p$ $>0.05$ in both cases). In contrast, birds dosed with $24 \mu \mathrm{g} / \mathrm{g}$ MMA $(\mathrm{V})\left(t_{6}=2.73, p<0.05\right)$ and $72 \mu \mathrm{g} / \mathrm{g}$ MMA $(\mathrm{V})\left(t_{6}\right.$ $=5.09, p<0.01$ ) showed significant mass loss (Table 2). Hematocrit did not differ among treatment groups (ANOVA, $p>0.05$; Table 2) and mean hematocrit was $56.7 \%( \pm 2.3 \%)$. Similarily, leucocrit did not differ among treatment groups (ANOVA, $p>0.05$; Table 2), and the mean leucocrit value was $6.3 \%( \pm 1.5 \%)$.

\section{DISCUSSION}

On average, zebra finches dosed with environmentally relevant concentrations of $0,8,24$, and $72 \mu \mathrm{g} / \mathrm{g}$ MMA (V) for $14 \mathrm{~d}$ excreted more than $90 \%$ of the overall total arsenic detected, with low levels of arsenic in the blood and tissues. Fecal samples from the low and medium dose groups show small amounts of arsenic on day 1, with a large increase by day 7. Results from the low and medium dose groups suggest that zebra finches are initially accumulating the ingested MMA (V), and excreting less. They may then reach a threshold where tissues become saturated, at which point they start to excrete much more of the ingested MMA (V) with little absorption. Results from the high dose group do not exhibit this trend, and birds appear to excrete large amounts of the ingested MMA (V) on both days 1 and 14, with a decrease on day 7. Zebra finches accumulated arsenic in a dose-dependent manner in all tissues. Similarly, broiler chickens dosed with 100 and 500 $\mathrm{mg} / \mathrm{kg}$ arsinilic acid accumulated up to 2.3 and $8 \mathrm{mg} / \mathrm{kg}$ arsenic in the liver tissue and 0.15 and $0.67 \mathrm{mg} / \mathrm{kg}$ arsenic in muscle tissue, respectively [24]. Moreover, mallards fed 25, 100, or $400 \mathrm{mg} / \mathrm{kg}$ sodium arsenate accumulated arsenic in a dosedependent manner, with arsenic in adult mallard livers ranging from 0.49 to $6.6 \mathrm{mg} / \mathrm{kg}$ [25].

The high excretion and low tissue retention results of the present experiment are also similar to those reported by previous studies in mammals. Oral administration of a single 50 $\mathrm{mg} / \mathrm{kg}$ body weight dose of MMA to hamsters resulted in excretion of $94.5 \%$ (urine + feces) of the administered dose [4]. Rats injected with MMA also directly excreted the com- pound in its original form, with low uptake into the tissues [26]. Similarly, sheep and goats orally dosed with $10 \mathrm{mg}$ MSMA/kg body weight excreted over $90 \%$ of the arsenic within $120 \mathrm{~h} \mathrm{[5]} \mathrm{and} \mathrm{mice} \mathrm{injected} \mathrm{with} 8.04 \mathrm{nmol} / \mathrm{kg}$ and 804 $\mu \mathrm{mol} / \mathrm{kg}$ MMA showed rapid elimination as well, with low tissue retention $(<2 \%$ of dose) [27].

Zebra finches and other species studied show low concentrations of MMA (V) in tissues with most of the arsenic being excreted in the original MMA (V) form. These results could suggest that the MMA (V) is not readily taken up by the gastrointestinal tract and is instead excreted unchanged with only trace amounts being absorbed by the gastrointestinal tract and redistributed to the tissues and metabolized. Alternatively, since DMA (V) is detected in small amounts in the tissues, MMA (V) may be readily taken up by the gastrointestinal tract and then primarily eliminated in the bile with only trace amounts of the compound being taken up and metabolized by the tissues. While there appear to be trends in tissue retention and elimination patterns of MMA (V) among species, there are differences in specific target tissues and patterns of distribution among species. For example, most of the remaining arsenic in the zebra finches was found in the carcass, followed in order of decreasing total arsenic by the blood, brain, kidney, and liver. In hamsters dosed with MMA (V), the highest tissue concentration of total arsenic was in the kidney, followed by the spleen, lung, skin, liver, muscle, hair, and brain [4]. In contrast, mice injected with MMA (V) had the highest arsenic levels in the carcass, followed by the liver, kidney, and the lung [27]. Of the organs analyzed, the brain had the most arsenic in the zebra finches. Arsenic has the ability to cross the blood-brain barrier. It has been to shown to accumulate in the brain and cause neurotoxic effects in rats by altering adenosine triphosphate metabolism and influencing neurons and glia [28,29]. Future studies should be conducted to determine any neurotoxic effects of MMA (V) to pesticide-exposed passerines.

Timing of sampling may play a role in the distribution of arsenic in the blood and tissues. Ingested methylated arsenicals have biological half-lives of approximately $30 \mathrm{~h}$ [30]. In the present study, zebra finch tissues and blood were sampled after two weeks of MMA (V) dosing, approximately $24 \mathrm{~h}$ after the last dose. In a similar study, hamsters dosed with a single oral dose of $50 \mu \mathrm{g} / \mathrm{g}$ MMA were sampled after 1, 6, 12, 24, 72, and $120 \mathrm{~h}$ after administration [4]. Peak arsenic tissue concentrations occurred between 6 and $12 \mathrm{~h}$ after administration, with maximum concentrations of $0.21 \mu \mathrm{g} / \mathrm{g}$ in the liver, 1.99 $\mu \mathrm{g} / \mathrm{g}$ in the kidney, and $0.04 \mu \mathrm{g} / \mathrm{g}$ in the brain. These concentrations dropped back to control levels by $120 \mathrm{~h}$ [4]. Tissue distribution results from the present study may have differed had we sampled at different times. Sampling $24 \mathrm{~h}$ after the 
last dose may have yielded slightly lower tissue residue concentrations than if we had samples 6 or $12 \mathrm{~h}$ post dose. Zebra finches may have had time to metabolize and excrete much of the last dose by the time we collected tissues.

Monomethylarsonic acid is the predominant form of arsenic found in the plasma and feces of zebra finches dosed with MMA (V), while the tissues had much higher levels of DMA (V). The minimal excretion of DMA (V) following MMA (V) administration is in accord with related studies. The hamster [4] and human [31] excrete primarily MMA (V) following MMA (V) administration. It has been suggested that this lack of methylation to DMA (V) in vivo may be due to the rapid elimination of MMA (V) in urine, or the low uptake into tissues with high methylating capacities [27]. Monomethylarsonic acid may not have time to undergo methylation to DMA (V), and that this methylation may not occur as quickly as methylation from arsenite to MMA (V) [27]. If the zebra finches are indeed absorbing the MMA (V), this may hold true for the present study, since large amounts of MMA (V) were excreted after only one dose (Fig. 3) A large portion of the arsenic taken up by the liver and kidney was methylated, as these tissues contained primarily DMA (V) (83 and $61 \%$ respectively). This is to be expected as these organs, especially the liver, are where most metabolism of orally ingested toxins takes place. Arsenic is metabolized in the liver by methyltransferases, and there are differences in these enzymes between animal species [32]. Zebra finches showed the ability to methylate MMA (V) to DMA (V), as DMA (V) was the predominant arsenic species in the liver and kidney. Similarly, the rat, rabbit, hamster, and pigeon all have methyltransferases in the liver [33-36]. In contrast, the guinea pig, marmoset monkey, squirrel monkey, and tamarin lack these enzymes and are unable to methylate arsenite or MMA (V) [36].

Assessment of the toxicity of MSMA to zebra finches is limited by our inability to distinguish between oxidation states. Elucidation of valency is important, as this drives the toxicity of arsenic species. Generally, trivalent arsenicals are more cytotoxic than pentavalent arsenicals. Trivalent inorganic arsenic, As (III), is more acutely toxic than pentavalent inorganic arsenic, As (V) [6,7], with MMA (III) the most toxic methylated arsenical species $[7,8]$. Based on the postulated metabolic pathway, MMA (V) would first be reduced to its trivalent analog MMA (III), followed by further methylation to DMA (V) and possible reduction to DMA (III) (Fig. 1) [37]. Glutathione and other thiols serve as reducing agents, and S-adenosylmethionine is the main methyl donor [33]. In the present study, both MMA and DMA were detected in the blood, feces, and organ tissues of zebra finches dosed with MMA (V). Thus, we suggest that zebra finches were exposed to the highly toxic intermediate MMA (III) during metabolic conversion of MMA (V) to DMA (V). However, since MMA (III) is very unstable, it is likely that any MMA (III) produced was quickly methylated to DMA (V). As discussed earlier, MMA (III) has the ability to inhibit enzymes such as glutathione reductase [11], altering cellular redox reactions and leading to cytotoxicity [12]. This may explain the observed toxic effects, namely weight loss, in the zebra finches. Finally, inorganic arsenic detected in the liver tissue $(5 \%)$ can most likely be attributed to background levels resulting from natural exposure to arsenic in food and drinking water. Although there was no inorganic arsenic detected in fecal samples or other tissues, this is the most parsimonious explanation, as demethylation of MMA (V) to inorganic arsenic is highly unlikely [4,37].
The two highest dose groups lost up to $15 \%$ of initial body mass over 14 d. Ingested MSMA can cause diarrhea [38], leading to dehydration and mass loss. There was however no observable differences in quantity or texture of feces between dose groups. Dehydration may also increase hematocrit and we found no change in hematocrit with MSMA treatment. Ingestion of MSMA causes gastrointestinal inflammation [38]. This may result in a decrease in appetite and subsequently decreased food intake, or malabsorption of food and nutrients, perhaps resulting in a decrease in overall body mass over a two-week period.

In the present study zebra finches were used as a model to determine effects of MMA (V) exposure in avian species. In the wild, woodpeckers and other insectivorous forest birds are exposed to this compound. Blood sample results from woodpeckers exposed to the parent compound MSMA via ingestion of contaminated bark beetles in the Merritt Forest District in British Columbia ranged from 0.03 to $3.73 \mu \mathrm{g}$ arsenic/g dry weight blood [2]. Mountain chickadees (Poecile gambeli) in the same district had total blood arsenic levels of up to 2.20 $\mu \mathrm{g} / \mathrm{g}$ [2]. Zebra finches in the present study dosed with presumably the same environmentally relevant concentrations of MMA (V) had total blood arsenic values ranging from 0.05 to $6.02 \mu \mathrm{g} / \mathrm{g}$. Based on those total blood arsenic results, we suggest that woodpeckers may accumulate similar tissue concentrations of arsenic in the field and could also experience health effects, such as decreased body mass, when exposed to similar concentrations. However, woodpeckers and other insectivorous birds likely experience long-term exposure to MSMA, rather than a 14-d period. Longer-term sublethal dosing of birds to heavy metals such as aluminum, cadmium, mercury, and lead can cause subtle but marked toxic effects such as reproductive dysfunction, behavioral abnormalities, and increased susceptibility to additional stressors such as disease [39]. Zebra finches exposed to levels of MMA (V) detected in bark beetle samples in MSMA treated stands of trees exhibited mass loss over the subacute time period of $14 \mathrm{~d}$. However, longer term exposure to this compound may cause significant effects that may otherwise go undetected in $14 \mathrm{~d}$. Therefore, the effects of long-term exposure of MSMA and its metabolites on uptake, elimination, and toxicity should be further studied. If the goal is to determine population level effects of chronic exposure to methylated arsenicals, studies carried out over more than one generation may be beneficial. The result of such exposure may better provide an understanding of the consequences for forest birds exposed to MSMA as well as forestry management implications.

Acknowledgement-Funding was provided by the Pesticide Science Fund and Canadian Wildlife Service of Environment Canada. Housing for the zebra finches was provided by the Animal Care Facility (Simon Fraser University, Burnaby, BC, Canada).

\section{REFERENCES}

1. Dost FN. 1995. Public health and environmental impacts of monosodium methanearsonate as used in bark beetle control in British Columbia. FS 48 HIS 95/2. Technical Report. Ministry of Forests, Victoria, BC, Canada.

2. Morrissey C, Elliott JE, Dods P, Albert CA, Wilson L, Lai V, Cullen WR. 2006. Assessing forest bird exposure and effects from monosodium methanearsonate (MSMA) during the mountain pine beetle epidemic in British Columbia. Canadian Wildlife Service Technical Report 460. Pacific and Yukon Region, Delta, BC.

3. MMA Task Force Three. 1993. SARA Title III Section 313 Delisting petition for monosodium methanearsonate (MSMA) and 
disodium methanearsonate (DSMA). ISK Biotech, Mentor, OH, USA.

4. Yamauchi H, Yamato N, Yamamura Y. 1988. Metabolism and excretion of orally and intraperitoneally administered methylarsonic acid in the hamster. Bull Environ Contam Toxicol 40:280286.

5. Shariatpanahi M, Anderson AC. 1984. Distribution and toxicity of monosodium methanearsonate following oral administration of the herbicide to dairy sheep and goats. J Environ Sci Health B 19:427-439.

6. Yamauchi H, Fowler BA. 1994. Toxicity and metabolism of inorganic methylated arsenicals. In Nriagu JO, ed, Arsenic in the Environment, Part II: Human Health and Ecosystem Effects. John Wiley, New York, NY, USA, pp 35-53.

7. Styblo M, Del Razo LM, Vega L, Germolec DR, LeCluyse EL, Hamilton GA, Reed W, Wang C, Cullen WR, Thomas D. 2000. Comparative toxicity of trivalent and pentavalent inorganic and methylated arsenicals in rat and human cells. Arch Toxicol 74: 289-299.

8. Petrick JS, Ayala-Fierro F, Cullen WR, Carter DE, Vasken Aposhian H. 2000. Monomethylarsonous acid (MMA III) is more toxic than arsenite in Chang human hepatocytes. Toxicol Appl Pharmacol 163:203-207.

9. Yamauchi H, Yamamura Y. 1985. Metabolism and excretion of orally administered arsenic trioxide in the hamster. Toxicology 34:113-121.

10. Aposhian HV. 1989. Biochemical toxicology of arsenic. In Hodgson E, Bend JR, Philpot RM, eds, Reviews in Biochemical Toxicology. Elsevier, New York, NY, USA, pp 265-299.

11. Styblo M, Serves SV, Cullen WR, Thomas DJ. 1997. Comparative inhibition of yeast glutathione reductase by arsenicals and arsenothiols. Chem Res Toxicol 10:27-33.

12. Hughes MF. 2002. Arsenic toxicity and potential mechanisms of action. Toxicol Lett 133:1-16.

13. Kuroda K, Yoshida K, Yoshimura M, Endo Y, Wanibuchi H, Fukushima S, Endo G. 2004. Genotoxicity of dimethylarsinous acid: High induction of tetraploids. Appl Organomet Chem 19: 221-225.

14. Eguchi N, Kuroda K, Endo G. 1997. Metabolites of arsenic induced tetraploid and mitotic arrest in cultured cells. Arch Environ Contam Toxicol 32:141-145.

15. Wanibuchi H, Yamamoto S, Chen H, Yoshida K, Endo G, Hori T, Fukushima S. 1996. Promoting effects of dimethylarsinic acid on $N$-butyl-(4-hydroxybutyl)nitrosamine-induced urinary bladder carcinogenesis in rats. Carcinogenesis 17:2435-2439.

16. Yamamoto S, Konishi Y, Matsuda T, Murai T, Shibata MA, Matsui-Yuasa I, Otani S, Kuroda K, Endo G, Fukushima S. 1995. Cancer induction by an organic arsenic compound, dimethylarsinic acid (cacodylic acid), in F344/DuCrj rats after pre-treatment with five carcinogens. Cancer Res 55:1271-1276.

17. Crockett AB, Hansley PL. 1978. Apparent response of Picoides woodpeckers to outbreaks of the pine bark beetle. West Birds 9: $67-70$.

18. Koplin JR. 1972. Measuring predator impact of woodpeckers on spruce beetles. $J$ Wildl Manag 36:308-320.

19. Nagy KA. 2001. Food requirements of wild animals: Predictive equations for free-living mammals, reptiles, and birds. Nutr Abstr Rev Series B 71:21R-31R.

20. Dunning JB Jr. 1993. Handbook of Avian Body Masses. CRC, Boca Raton, FL, USA.

21. Ots I, Murumagi A, Horak P. 1998. Haematological health state indices of reproducing great tits: Methodology and sources of natural variation. Funct Ecol 12:700-707.
22. Wardlaw SC, Levine RA. 1983. Quantitative buffy coat analysis: A new laboratory tool functioning as a screening complete blood count. J Am Med Assoc 249:617-620.

23. Lai V, Yongmei S, Ting E, Cullen WR, Reimer KJ. 2004. Arsenic speciation in human urine: Are we all the same? Toxicol Appl Pharmacol 198:297-306.

24. VanderKop PA, MacNeil JD. 1989. Effects of arsanilic acid and monensin when given simultaneously in the diet of broiler chicks. Vet Hum Toxicol 31:209-213.

25. Stanley TR, Spann JW, Smith GJ, Rosscoe R. 1994. Main and interactive effects of arsenic and selenium on mallard reproduction and duckling growth and survival. Arch Environ Contam Toxicol 26:444-451.

26. Suzuki KT, Katagiri A, Sakuma Y, Ogra Y, Ohmichi M. 2004. Distributions and chemical forms of arsenic after intravenous administration of dimethylarsinic and monomethylarsonic acids to rats. Toxicol Appl Pharmacol 198:336-344.

27. Hughes MF, Kenyon BM. 1998. Dose-dependent effects on the disposition of monomethylarsonic acid and dimethylarsinic acid in the mouse after intravenous administration. J Toxicol Environ Health Part A 53:95-112.

28. Nagaraju TN, Desiraju T. 1993. Regional alterations in the levels of brain biogenic amines, glutamate, GABA, and GAD activity due to chronic consumption of inorganic arsenic in developing and adult rats. Bull Environ Contam Toxicol 50:100-107.

29. Valkonen S, Savolainen H, Järvisalo J. 1983. Arsenic distribution and neurochemical effects in peroral sodium arsenite exposure of rats. Bull Environ Contam Toxicol 30:303-308.

30. Klaasen CD, ed. 2001. Casarett and Doull's Toxicology; The Basic Science of Poisons. McGraw-Hill, New York, NY, USA.

31. Buchet JP, Lauwerys R, Roels H. 1981. Comparison of the urinary excretion of arsenic metabolites after a single oral dose of sodium arsenite, monomethylarsonate, or dimethylarsinate in man. Int Arch Environ Occu Health 48:71-79.

32. Healy SM, Wildfang E, Zakharyan RA, Aposhian HV. 1999. Diversity of inorganic arsenite biotransformation. Biol Trace Elem Res 68:249-266.

33. Buchet JP, Lauwerys R. 1988. Role of thiols in the in vitro methylation of inorganic arsenic by rat liver cytosol. Biochem Pharmacol 37:149-153.

34. Zakharyan RA, Wu Y, Bogdan GM, Aposhian HV. 1995. Enzymatic methylation of arsenic compounds. I. Assay, partial purification, and properties of arsenite methyltransferase and monomethylarsonic acid methyltransferase of rabbit liver. Chem Res Toxicol 8:1029-1038.

35. Zakharyan RA, Wildfang E, Aposhian HV. 1996. Enzymatic methylation of arsenic compounds. III. The marmoset and tamarind, but not the rhesus, monkey are deficient in methyltransferases that methylate inorganic arsenic. Toxicol Appl Pharmacol 140:77-84.

36. Cullen WR, McBride BC, Reglinski J. 1984. The reaction of methylarsenicals with thiols: Some biological implications. J Inorg Biochem 21:179-194.

37. Marafante E, Vahter M, Norin H, Envall J, Sandstrom A, Christakopoulos A, Ryhage R. 1987. Biotransformation of dimethylarsinic acid in mouse, hamster and man. J Appl Toxicol 7:111117.

38. Jaghabir MTW, Abdelghani A, Anderson AC. 1988. Oral and dermal toxicity of MSMA to New Zealand white rabbits, Oryctalagus cuniculus. Bull Environ Contam Toxicol 40:119-122.

39. Scheuhammer AM. 1987. The chronic toxicity of aluminum, cadmium, mercury, and lead in birds: A review. Environ Pollut 46: 263-295. 